\title{
The Effect of Academic Development Initiatives on Student Performance at a South African University: A Case of Finance Modules
}

\author{
Paul-Francois Muzindutsi \\ PhD Candidate, School of Economic Sciences, \\ North-West University, South Africa \\ muzindutsi@gmail.com
}

\section{Doi:10.5901/mjss.2013.v4n3p717}

\begin{abstract}
The retention and the success of undergraduate students is a concern in South African universities which have been faced with a major challenge of low graduation rates. To respond to this challenge, South African universities adopted various academic development initiatives to provide support to students who are at risk of not completing the undergraduate qualification within the required time. This study used multiple regression analysis to evaluate the contribution of academic development initiatives in improving the academic performance of 'at risk' students within discipline of finance at the University of KwaZulu-Natal in South Africa, during the period 2009-2011. Results showed that some of the initiatives, such as revision workshops, contributed significantly to student performance while others, such as one-on-one consultations between students and Academic Development Officers (ADO's), had no significant effect on student performance. This study found that making academic development initiatives inclusive to all willing students did not disadvantage 'at risk' students. It was therefore concluded that academic development initiatives can only succeed when there is full commitment from students involved. This study recommends that one-on-one discussions between students and ADO's should be supplemented by other strategies, such as timely and regular revision workshops, in order to yield positive results.
\end{abstract}

Keywords: academic development programme, at risk students, student performance

\section{Introduction}

The retention and success of students in their respective fields of study particularly in the context of under-represented student groups is a global concern for higher education institutions (Crosling, Heagney \& Thomas, 2009). Retention plays an important role in raising funds for universities as Departments of Education use the statistics from undergraduate retention to provide funding to universities (Scott \& Graal, 2007). Thus, the retention of students in their studies is a key performance indicator in university quality assurance processes. The retention and the success of the undergraduate students is a worldwide concern, especially in South Africa where the graduation rate of all first-time entering students was $30 \%$ in 2007(Fisher, 2011). One of the major causes of this low graduation rate in South Africa is a big number students entering university from positions of extreme inequality, most obviously in schooling, and financial problems (Council on Higher Education (CHE), 2010). To improve retention, the University of KwaZulu-Natal (UKZN) developed various initiatives. One of these initiatives is the Academic Development Programme (ADP) which involves responsibilities of providing academic support to students who are deemed to be at risk. In the context of UKZN, students are at risk when the number of modules they pass within a semester is below the minimum number required by the university; or when students are at risk of not completing their qualification within the required time. This description is in line with the definition provided by Slavain \& Madden (1990) who associated the term at risk with danger of failing to complete a qualification with an adequate level of skills or within the required time. Throughout this paper, the term at risk will refer to above description of at risk students by the University of KwaZulu-Natal.

The main objective of the UKZN ADP is to develop academic interventions that minimize the number of at risk students in order to increase the graduation rate. Within the Faculty of Management Studies, academic support is provided using Academic Development Officers (ADO's) who specialise in a specific module. This paper will therefore focus on the role of the ADO for finance modules in improving the academic success of undergraduate students in the School of Economics and Finance at the UKZN, Westville Campus. Based on the methods of teaching discussed by previous researchers (Kintsch \& Van Dijk, 1978; Slavain \& Madden, 1990; Pastoll, 1992; Felder \& Brent, 2005; Ogude, Kilfoil, \& du Plessis, 2012), the ADO developed methods of intervention to address some of the academic challenges 
faced by at risk students. Such methods of intervention include: the improvement of reading and writing skills, through the submission of summaries of textbook chapters to the ADO; the promotion of analytical and critical thinking through revision workshops and enhancement of deep understanding of terminology in the discipline through one-on-one discussions between students and ADO's. Thus, this paper seeks to evaluate the effect of these interventions on the academic performance of finance undergraduate students during the period 2009-2011. The rest of this paper is as follows: Section 2 reviews the literature; Section 3 explains the methodology; Section 4 provides the results and discussion and Section 5 concludes the paper.

\section{Literature review}

The Academic Development Programme (ADP) at the University of KwaZulu-Natal involves providing academic support to students who are deemed to be at risk. Slavain \& Madden (1987) explain that students are at risk of academic failure due to different factors including- low socioeconomic status, low measured ability, learning disability or learning problems, low achievement and poor attendance. At risk students are therefore in danger of failing to complete the academic qualification with an adequate level of skills (Slavain \& Madden, 1990). Risk factors are also linked to significant outcomes of previous schooling which may have their roots in the early school years and extended to the lack of engagement in the classrooms (Finn \& Rock, 1997). In South Africa, the main risk factors include poor class attendance, inadequate preparation, insufficient time, lack of a good foundation from previous schooling and financial challenges; which lead to part time work (Steenkamp, Baard \& Frick, 2009; CHE, 2010). Hence, the major role of South African higher education institutions is to develop strategies that address these risk factors.

Some of the strategies used in dealing with at risk students are pull-out programmes (pulling at risk students out of the classroom for special attention) and in-class (keeping at risk students in the classroom or a diverse group but providing them with additional support, such as revision lectures and additional tutorials) (Slavain \& Madden, 1987). The difference between these two strategies is that the pull-out strategy provides support to a group of underperforming (at risk) students only, while the in-class strategy supports at risk students together with other students who are performing well. The finance ADO initially adopted pull-out programmes, where only at risk students were requested to attend the ADP initiatives (mainly revision workshops and one-on-one consultations). However, some students felt very embarrassed at being identified as part of the at risk students and hence did not attend these ADP initiatives. This is a major weakness of the pull-out strategies because these strategies label students instead of integrating them (Johnston, Allington, \& Aflerba, 1985). To avoid the challenges associated with the pull-out strategy, an alternative strategy, where the ADP initiatives were extended to all interested students, was adopted by the finance ADO. This inclusive strategy allowed at risk students to discuss and engage with other non-risk students who viewed ADP initiatives as an opportunity to improve their performance. This was expected to be a successful approach as understanding is constructed through discussion and engagement (Fisher et al., 2010). In additon to this , at risk students were encouraged to attend lectures. Gracia \& Jenkins(2002) emphasise that attendance is correlated with academic success.

Previous studies (Friedman, Rodriguez \& McComb, 2001; Massingham \& Herrington, 2006; Thatcher, Fridjhon \& Cockcroft, 2007; Ryan, Delaney \& Harmon, 2010; Van Schalkwyk, Menkveld \& Ruiters, 2010) indicated that attending lectures, tutorials and any other academic support is one of the positive predictors for the academic success of university students. These studies emphasised that lecture attendance is attributed to the qualities and skills that the lecturers, tutors and other facilitators bring into the classroom. However, it is important to note that attending may not yield results if students do not take part in the discussions conducted in the lecture rooms. Gracia \& Jenkins (2002) state that students that perform poorly generally do not participate in class activities as they feel anxious, lack confidence and therefore fear the reactions they may get from their peers and tutors if they give incorrect answers. These underperforming students are of the notion that the lecturer is responsible for providing learning and that they are mere passive recipients. The ADP encourages such underperforming (at risk) students to form individual study groups and to actively participate in lecture and tutorial discussions. Moreover, ADP initiatives, such as workshops and group discussions, provide a good platform for underperforming (at risk) students to develop confidence which could improve their engagement during lectures and tutorials. It is therefore important to evaluate whether or not such ADP initiatives contribute to the improvement of student performance. 


\section{Methodology}

\subsection{Data}

The participants of this study were undergraduate students (within the discipline of finance) from the University of KwaZulu-Natal, Westville Campus in South Africa. The sample comprised of second and third year students who used the ADP services from 2009 to 2011. Second year students were registered for one finance module each semester (Finance 201 and 202), while third year students took two finance modules in semester one (Finance 311 and 312) and one module in semester two (Finance 321). The sample size constituted a total number of 282 students who used at least one of the ADP services from 2009 to 2011.

The variables used by this study include: students' final marks, number of revision workshops attended by a student and the number of one-on-one discussions between a student and the ADO and dummy variables for gender, level of study and the year of registration with ADO services. The data used came from the records kept by the Finance $A D O$ as well as academic records from the university's Division of Management Information (DMI). Ethical clearance was obtained from UKZN's Ethics Committee before the research project commenced.

\subsection{Model}

To analyse the data, this study used descriptive statistics (such as mean, standard deviation and correlation coefficients) as well as multiple regression analysis. Since, there was a combination of continuous and dummy variables; the regression model used is described as an analysis of covariance model (Gujarati, 2003) and is presented as follows:

$S M_{i}=\beta_{1}+\beta_{2} R W_{i}+\beta_{3} I C_{i}+\beta_{4} D_{1 i}+\beta_{5} D_{2 i}+\beta_{6} D_{3 i}+u_{i}$

Where: $S M_{i}=$ final marks (in percentage) obtained by a student (i);

$\left.R W_{i}\right)=$ the number of revision workshops attended by a student (i) within a semester;

$I C_{i}=$ the number of individual consultations (one-on-one discussions) with the ADO during a semester;

$D_{1 i}$ is a dummy variable for the level of study which compares third year to second year students ( $D=1$, if a student (i) is a third year student and 0 , otherwise);

$D_{2 i}$, is a dummy variable for gender ( $\mathrm{D}=1$, if a student (i) is female and 0 , otherwise)

$D_{3 i}$, is a dummy variable comparing a year $2009^{1}$ to the years 2010 and 2011 ( $D=1$, if a student (i) used ADP services in 2009 and 0 , otherwise);

$\beta_{2}, \beta_{2}, \ldots \beta_{6}=$ coefficients; and

$\beta_{1}$ and $u_{i}=$ the intercept and the error term, respectively.

STATA 11 was used to estimate the above equation (1) and the significance of the variables are tested using the t-test or p-values. The hypothesis test is set as follows:

The null hypothesis $\left(\mathrm{H}_{0}\right): \beta i=0$

The alternative hypothesis $\left(\mathrm{H}_{1}\right): \beta i \neq 0$

The estimated t-ratios were compared to the critical values from the t-table. Where the estimated t-value was greater than the critical t-value then $\mathrm{H}_{0}$ was rejected this means that the variable has a significant impact on student performance. If $\mathrm{H}_{0}$ is not rejected, the variable does not have a significant impact on student performance. Before interpreting the results, diagnostic tests were conducted to establish whether the model meets basic assumption associated with a linear regression. These basic assumptions are: normality, partial autocorrelation, collinearity, homogeneity and homoscedasticity (Gujarati, 2003). If the model fails to meet any of these assumptions, a generalised linear model is used.

\section{Results and Discussion}

\subsection{Descriptive statistics}

A summary of descriptive statistics and correlation coefficients with P-values are in Table1 and 2, respectively. During the period of 3 years, a total number of 282 finance students used the ADP services. $60.06 \%$ of the total number of these students were registered for the third year modules, while the remaining percentage was registered for second year

${ }^{1}$ Year 2009 is used as a benchmark in order to test the impact of extending the ADP services to non- risk students on students' performance. 
modules. In terms of gender, females constituted $55.31 \%$ of the total number of the students considered for this study, while males constituted the remaining $44.69 \%$. A comparison across the years shows that the number of finance students who attended the ADP initiatives increased from 77 in 2009 to 119 in 2011, and this was a result of extending the ADP initiatives to all interested finance students instead of limiting the services to at risk students. The standard deviation for the whole period was $12.10 \%$ and decreased from $14.66 \%$ in 2009 to $10.57 \%$ in 2011 . This suggests that the strategy of extending the ADP initiatives to all interested students reduced the deviation of marks. The maximum and minimum marks were $84 \%$ and $18 \%$, respectively, while the average mark for the whole period was $55.22 \%$ per student. The average number of one-on-one discussions per semester was 7 consultations per student, while the number of revision workshops attended by a student was 3 per semester. These descriptive statistics suggest that the third year students tended to be committed to ADP initiatives as compared to the second year students and that the strategy of keeping at risk students in a diverse group yields positive results.

Table1: Descriptive statistics

\begin{tabular}{lcccc}
\hline & Year 09 & Year 10 & Year 11 & Whole period \\
\hline Descriptive of the marks (\%): & & & & \\
Mean & 55.52 & 56.2 & 54 & 52.25 \\
Maximum & 84 & 78 & 76 & 84 \\
Minimum & 26 & 21 & 18 & 18 \\
Standard deviation & 14.66 & 11.54 & 10.57 & 12.10 \\
\hline Gender distribution: & & & & \\
Number of male students & 35 & 36 & 55 & 126 \\
Number of female students & 42 & 50 & 64 & 156 \\
\hline Level of study: & 26 & 27 & 58 & 111 \\
Number of students in 2nd year & 51 & 59 & 61 & 171 \\
Number of students in 3rd year & 6.61 & 7.7 & 7 & 6.96 \\
\hline Average no. of individual consultations & 3.33 & 3.42 & 3 & 3.28 \\
Average no. of revision workshops & 77 & 86 & 119 & 282 \\
Total number of students & & & & \\
\hline
\end{tabular}

All coefficients of correlation, in Table 2, are significant at $1 \%$ level of significance; meaning that there is a high level of association between student performance and revision workshops, individual consultations and level of study. The positive signs of the correlation coefficient suggest that there is a positive relationship between the student marks and these variables. The correlation coefficients are in line with the assumption that ADP initiatives were expected to have a positive effect on student performance. However a further analysis is needed to confirm these relationships.

Table 2: Pearson Correlation coefficients

\begin{tabular}{|c|c|c|c|}
\hline & Revision Workshop & Individual Consultations & Level Study \\
\hline Student & $0.2889^{*}$ & $0.1763^{\star}$ & $0.3744^{*}$ \\
Marks & $(0.000)$ & $(0.0030)$ & $(0.000)$ \\
\hline
\end{tabular}

* Significant at $1 \%$ level of significance, P-values within the brackets

\subsection{Multiple regression analysis}

The estimates of multiple regressions, in Table 3, show that only 2 variables (Revision workshops, RW and dummy for level of study, $D_{1}$ ) have a significant effect on student marks at the $1 \%$ level of significance. Holding other factors constant, one additional revision workshop increased the total marks buy $1.90 \%$. This was highly expected, as the revision workshops attracted students because they were conducted regularly prior to the tests and examinations. Additionally, these workshops prepared students for tests and examinations by encouraging students to take part in the discussions on challenging topics identified by the ADO. On average, being a third year student increased the total marks by $9.25 \%$ as compared to being a second year student, when other factors are held constant. This is explained by the high level of commitment to the academic development initiatives shown by third year students; especially those who were determined to complete their qualifications on time. Thus, the commitment of students to the ADO initiatives plays an important role towards the success of the academic development initiatives. These findings are supported by previous 
researchers (Romer, 1993; Gracia \& Jenkins, 2002; Fraser \& Killen, 2003) who associated good academic success with factors such self-motivation, timely and regular examination preparation, and students' interest in class discussions.

Table 3: Regression results²

\begin{tabular}{ccccc}
\hline \multicolumn{2}{c}{ Dependent Variable: SM } & \multicolumn{3}{c}{ Included observations: 282 } \\
\hline Variable & Coefficient & Std. Error & t-Statistic & Prob. \\
\hline RW & 1.920443 & 0.653353 & 2.94 & 0.0041 \\
IC & 0.204177 & 0.310813 & 0.66 & 0.5120 \\
$\mathrm{D}_{1}$ & 9.156885 & 1.368641 & 6.69 & 0.0000 \\
$\mathrm{D}_{2}$ & 0.264752 & 1.318966 & 0.20 & 0.8410 \\
$\mathrm{D}_{3}$ & -0.352918 & 1.456839 & -0.24 & 0.8090 \\
$\mathrm{C}$ & 41.9285 & 1.981452 & 21.16 & 0.0000 \\
\hline R-squared & 0.2160 & F-statistic $(5,276)$ & 15.21 \\
Adjusted R-squared & 0.2018 & \multicolumn{4}{c}{ Prob(F-statistic) } & 0.0000 \\
\hline
\end{tabular}

Variables such as the number of individual consultations (IC), gender $\left(D_{1}\right)$, the dummy variable for the year of 2009 are not statistically significant. Surprisingly, the individual consultations between a student and the ADO did not have a significant impact on the student marks. One possible cause of this is that the individual (or one-on-one) consultations were not only limited to academic challenges. Such consultations covered a range of non-academic issues such as social and emotional problems faced by at risk students; suggesting that individual consultations may not have a direct effect on students' marks. However, it is important to acknowledge that these individual consultations may have an indirect impact, such as change of attitude, on student performance, especially in the long-run (Fraser \& Killen, 2003). Furthermore, at risk students were required to consult the ADO on a weekly basis and some of these students visited the ADO's office for the sake of completing their consultation records. Hence, they did not benefit from these individual consultations. In order to produce positive results, the individual consultations should be supplemented by other strategies which engage students. The negative sign of $D_{3}$ shows that the 2009 strategies (of limiting academic development initiatives to at risk students only) did somehow have a negative effect on student performance. However, this effect was not statistically significant. Thus, the strategy of extending the ADP initiatives to all willing students, adopted in 2010 and 2011, did not disadvantage at risk students. This strategy attracted students of different experiences, study skills and interests which helped to enhance student engagement (Crosling et al., 2009). Finally, the value of the $\mathrm{R}^{2}$ indicates that variables considered in the model explain $20.18 \%$ of the students' marks and the P-value for F-statistics is significant at the $5 \%$ level of significance. This suggests that all independent variables jointly have a significant impact on students' marks. However, it is important to acknowledge that improvement of student performance cannot only be attributed to the variables considered in this study.

\section{Conclusion}

This study evaluates the effect of ADP initiatives developed to assist at risk undergraduate students in the discipline of finance at the University of KwaZulu-Natal, during the period 2009-2011. These initiatives mostly included revision workshops and individual discussions between students and the ADO. Results of this study showed that revision workshops contributed significantly to the academic success of finance undergraduate students. The structure and the timing of these revision workshops were very important in producing positive results. Although individual consultations played a significant role in motivating and encouraging at risk students to use other support structures within the university, these consultations did not have a significant impact on students' marks. Individual consultations should therefore be supplemented by other strategies such as revision workshops. A comparison between second and third year finance students showed that third year students were committed to the ADP; and as a result, they benefited from the academic development initiatives. This suggests that the academic development initiatives can only succeed when there is full commitment from students involved. A dummy variable comparing year 2009 to other years was not statistically significant, suggesting that extending the academic development initiatives to all willing students did not disadvantage at risk students. It is therefore important to assist students in small groups (such as workshops) and having a diverse group with non-risk students tends to stimulate the discussion. 
Based on the findings of this study, the following are recommended: teaching and learning activities should focus on strategies that enhance the level of commitment from students; the structure of academic development initiatives should focus on discussion and group-based learning activities; and timely and regular revision workshops for tests and examination preparations should be enhanced in order to motivate students. As a final remark, it is important to acknowledge that the use of technology may assist in enhancing the ADP initiatives but the relevant types of technology to be used may be a point of discussion for future research.

\section{Acknowledgements}

I would like to thank Zandile Masango for giving feedback on earlier versions of the paper and her assistance in editing. Thanks also goes to the Faculty of Management Studies' Education Unit at the University of KwaZulu-Natal for facilitating the research process.

\section{References}

Council on Higher Education. (2010). Access and Throughput in South African Higher Education: Three Case Studies (Higher Education Monitor). Pretoria: The South African Council on Higher Education.

Crosling, G., Heagney, M., \& Thomas, L. (2009). Improving Student Retention in Higher Education. Australian Universities Review, 51 (2), 9-18.

Felder, R., \& Brent, R. (2005). Understanding Student Differences. Journal of Engineering Education, 94(1), 57-72.

Finn, J., \& Rock, D. (1997). Academic Success Among Students at Risk for School Failure. Journal of Applied Psychology, 82(2), 221234.

Fisher, A., Russell, K., MacBlain, S., Noel, P., Curry, A., \& MacBlain, A. (2010). Re-examining the culture of learning in ITE: engaging with the new demands of the 21st century. Critical and Reflective Practice in Education, 2, 92-102.

Fisher, G. (2011, October). Te role of Education in Closing the Skills Gap in South Africa. [Online] Available: http://www.ched.uct.ac.za/usr/ched/docs/Fisher_Higher\%20Education\%20role.pdf (January 12, 2013)

Fraser, W., \& Killen, R. (2003). . Factors influencing academic success or failure of first-year and senior university students: Do education students and lecturers perceive things differently? South African Journal of Education, 23(4), 254-262.

Friedman, P., Rodriguez, F., \& McComb, J. (2001). Why students do and do not attend classes: Myths and realities. College Teaching, 49(4), 124-133.

Gracia, L., \& Jenkins, E. (2002). An Exploration Of Student Failure On An Undergraduate Accounting Programme of Study. Accounting Education, 11 (1), 93-107.

Johnston, P., Allington, R., \& Aflerba, P. (1985). The Congruence of Classroom and Remedial Instruction. Elementary School Journal, 85, 465-477.

Kintsch, W., \& Van Dijk, T. (1978). Towards a Model of Text Comprehension and Production. Psychological review, 85, 363-394.

Massingham, P., \& Herrington, T. (2006). Does attendance matter? An examination of student attitudes, participation, performance and attendance. Journal of University Teaching and Learning Practice, 3(2), 82-103.

Ogude, N., Kilfoil, W., \& du Plessis, G. (2012). An institutional model for improving student retention and success at the University of Pretoria. The International Journal of the First Year in Higher Education, 3(1), 21-34.

Pastoll, G. (1992). Tutorials that work: A guide to running effective tutorials. Cape Town: Arrow Publishers.

Romer, D. (1993). Do students go to class? Should they? The Journal of Economic Perspectives, 7(3), 167-174.

Ryan, M., Delaney, L., \& Harmon, C. (2010). Does lecture attendance matter for grades?: Evidence from longitudinal tracking of Irish students. Belfield: University College Dublin.

Scott, J., \& Graal, M. (2007). Student Failure in First Year Modules in the Biosciences: An Interview Based Investigation. Bio Sciences Education, 10, 1-6.

Slavain, R., \& Maddan, N. A. (1987). Effective Classroom Programs for Students at Risk. Office of Educational Research and Improvement. Conference paper, 150, pp. 1-13.

Slavain, R., \& Madden, N. (1990). What Works for Students at Risk: A Research Synthesis. Michigan: Lawrence W. Lezotte, Publisher.

Steenkamp, L., Baard, R., \& Frick, B. (2009). Factors influencing success in first-year accounting at a South African university: A and students' perceptions. SA Journal of Accounting Research, 23(1), 113-140.

Thatcher, A., Fridjhon, P., \& Cockcroft, K. (2007). The relationship between lecture attendance and academic performance in an undergraduate psychology class. South African Journal of Psychology, 37(3), 656-660.

Van Schalkwyk, S., Menkveld, H., \& Ruiters, J. (2010). What's the story with class attendance? First-year students: Statistics and perspectives. South African Journal of Higher Education, 24(4), 630-645. 